\title{
DIREITOS DA CRIANÇA: JORNALISTAS, ONGS E O AGENCIAMENTO DA CIDADANIA
}

\author{
CHILD RIGHTS: JOURNALISTS, NGOS AND CITIZENSHIP \\ ORGANIZATION
}

\author{
Robson Dias ${ }^{1}$ \\ Recebido em 11/10/2011 \\ Aceito em 08/12/2011
}

\begin{abstract}
RESUMO
O exercício do jornalismo, na concepção iluminista, presume um Estado Democrático de Direito, Liberdade de Expressão e Liberdade de Imprensa. No Brasil, o jornalista profissional trabalha em prol dos princípios da Declaração Universal dos Direitos Humanos, além de defender os direitos individuais e coletivos do cidadão garantidos pela Constituição Federal. A partir deste contexto, surgiram vários organismos do Terceiro Setor com estratégias de agendamento de notícias na mídia, tendo a cidadania como valor inerente à atividade jornalística. A Agência de Notícias dos Direitos da Infância (ANDI) trabalha a pauta da infância e da adolescência no espaço midiático. Abordaremos o prêmio Jornalista Amigo da Criança como estratégia de mobilização de jornalistas em prol da promoção da pauta da infância e da adolescência.
\end{abstract}

Palavras-Chave: Jornalista. Cidadania. Terceiro Setor. Direitos da criança.

\begin{abstract}
In the illuminist concept, journalism presupposes democracy, freedom of expression and freedom of press. In Brazil, professional journalists work in defense of the Universal Declaration of Human Rights, in addition to defending individual and collective rights assured by the Federal Constitution. In this context a number of Third Sector institutions emerged with management strategies to obtain space in the media. They understand that citizenship in an essential value for journalistic activities. The Child Rights News Agency (Agência de Notícias dos Direitos da Infância - ANDI) discusses themes concerning children and teenagers in the media. This article analyzes the prize Journalist Child's Friend (Jornalista Amigo da Criança) as a mobilization strategy of journalists to get attention to topics related to Childhood and Adolescence.
\end{abstract}

Keywords: Journalist. Citizenship. Third Sector. Child rights.

\footnotetext{
${ }_{1}$ Doutorando em Comunicação, sob a orientação do Prof. Dr. Luiz Martins da Silva, no Programa de Pós-Graduação da Faculdade de Comunicação da Universidade de Brasília (PPGFAC/UNB). Vinculado aos projetos de pesquisa credenciados no CNPQ: A ideia do pós-Jornalismo (2010-2013) e O Jornalismo como Teoria Democrática (2006-2010).
} 


\section{Por uma definição: Terceiro Setor quanto aos recursos e à finalidade}

Terceiro Setor é uma expressão de conceituação precisa, mas comumente utilizada de forma errônea. $\mathrm{Na}$ verdade, o seu uso é feito como termo guarda-chuva no sentido de englobar tudo o que não é considerado nem Primeiro e nem Segundo Setor.

Fernandes (1994) teoriza que o Primeiro Setor (o ente público, o governo) faz investimentos em questões sociais. O Segundo Setor (o ente privado, o mercado) direciona fundos para questões corporativas. E o Terceiro Setor aplica recursos na geração de serviços de caráter público e social. Para o autor, este último setor, por ter características dos outros Setores, organiza-se numa estrutura desburocratizada e trabalho em prol de uma finalidade que não se esgota em si.

Fernandes (1994) conceitua o Terceiro Setor como um agente privado com finalidade pública. Assim, na classificação do autor:

Recursos públicos para fins públicos $=$ Estado

Recursos privados para fins privados $=$ Mercado

Recursos privados para fins públicos $=$ Terceiro Setor

Recursos públicos para fins privados $=$ Corrupção ${ }^{2}$

O Terceiro Setor é fruto da organização dos cidadãos $^{3}$ em ONGs na intervenção social em prol de um benefício comum. A associação é voluntária e motivada pelo alcance de um bem comum não efetivado pelo Estado e nem pelo Mercado.

Rossy (2006) segue a linha de pensamento sobre a constituição do termo Terceiro Setor na ênfase de uma negativa. A autora explica que:

Na literatura sobre Terceiro Setor, este se forma imediatamente, em contraposição, portanto, aos outros espaços sociais, o Estado e o mercado. Dessa forma, o Terceiro Setor se define pela negativa: não tem atribuições próprias ao Estado e não está organizado em função da produção e comercialização de bens. Em contraponto ao mercado e seus agentes, sobretudo, as organizações próprias do Terceiro Setor não têm finalidade de lucro.

\footnotetext{
${ }_{2}^{2}$ FERNANDES, Rubem César. Privado Porém Público: o Terceiro Setor na América Latina. Rio de Janeiro: Relume-Dumará, 1994. p. 21

${ }^{3} \mathrm{O}$ indivíduo em exercício dos direitos civis e políticos de garantias constitucionais. Ser cidadão ou não conota o grau de gozo dos ideais democráticos na vida social.
}

Do ponto de vista positivo, o Terceiro Setor seria aquele que realiza funções sociais relevantes para a sociedade sem o objetivo de produzir lucros. Por isso, é composto por organizações de direito privado sem fins lucrativos, mas, com finalidades que são públicas ou de interesse público ${ }^{4}$.

\section{Atuação das ONGs no Brasil}

As primeiras ONGs a se estruturarem no Brasil chegaram na década de 1950. Eram estrangeiras e tinham um perfil de fomento ao desenvolvimento do chamado Terceiro Mundo (durante a Guerra Fria) ${ }^{5}$. Não tiveram grande atuação durante o período mais enérgico do Governo Militar.

Com a abertura política do Governo Militar (1979), surgiram ONGs que defendiam os presos políticos, que lutavam contra torturas, além das campanhas das famílias de desaparecidos. O cenário social era tomado pelos Movimentos Sociais ${ }^{6}$.

Os Movimentos Sociais dos anos 1960 e 1970 reivindicavam identidade social e visibilidade para suas causas: a questão do feminismo, do divórcio e da liberação sexual são exemplos. Durante o período mais autoritário do Regime Militar (1968-1979), a ênfase das reivindicações não podia ser política. A efervescência social durante o período era tanta que influenciou até a religião: a Igreja Católica criou a Teologia da Libertação ${ }^{7}$, que dava apoio a muitas iniciativas que esboçavam ascender como reivindicações de classe social.

Com a Constituição de 1988, apelidada pelo parlamentar Ulisses Guimarães de Constituição

\footnotetext{
${ }^{4}$ ROSSY, Elizena. Mídia e Terceiro Setor - como as ongs promovem a Cultura de Paz. Dissertação (Mestrado em Comunicação), UNB. 2006. p. 49

${ }^{5}$ A luta político-econômica entre os sistemas Capitalista e Socialista, no século XX, polarizou o mundo em dois eixos. Durante o período, a classificação de Primeiro Mundo, Segundo Mundo e Terceiro Mundo era utilizada pelo eixo capitalista como índice de desenvolvimento dos países. ${ }^{6}$ Os principais movimentos sociais eram os estudantis, de lutas pelos direitos civis, pacifistas, contra o racismo, de afirmação positiva, associações de moradores, de bairros, de mães, de contracultura, etc.

${ }^{7}$ No Brasil, a Teologia da Libertação é um termo de Leonardo Boff que aliava a missão de salvação cristã da Igreja Católica à situação social humana. A chamada fé pelas obras. Uma ideia franciscana de libertação do homem das mazelas da vida: fome, pobreza, doença. E, somente assim, ele estaria livre para a vida devocional. Em miúdos, preferia abrir orfanatos e ajudar em ações sociais a evangelizar. Considerava que ajudar ao próximo em relação às demandas sociais era uma forma de revelar o amor de Deus por aquele necessitado. É como se o foco saísse do templo de adoração e fosse para as Santas Casas de Misericórdia, para as Pastorais de amparo social. Havia a designação 'entidades eclesiais de base' para se referir às frentes de ação.
} 
Cidadã, o cenário de efervescência social mudou. Muitas organizações, oriundas de discursos ativistas dos movimentos sociais (perspectiva de Sociedade Civil), foram institucionalizadas em organismos executivos (perspectiva Terceiro Setor) ${ }^{8}$.

Depois da promulgação da Constituição de 1988, com o contexto de volta da Democracia ao Brasil, o processo de institucionalização das ONGs conferiu uma conotação mais executiva aos organismos sociais.

Rebechi (2002) recupera esse período na seguinte análise:

As ONGs militantes são consideradas aquelas que nasceram nos anos 70 e 80 , provenientes de ações participativas, uma vez que faziam parte dos bastidores dos movimentos sociais populares urbanos, proporcionando a participação da sociedade civil na queda do Regime Militar e para retomada do processo democrático no país. Um dos alicerces das ONGs militantes foi a conquista de direitos relacionado à justiça social. As ONGs que herdaram estas características são aquelas que trabalham com questões relativas ao meio ambiente, à saúde, ao lazer, às deficiências físicas e mentais, ao vírus da AIDS etc. Isto é, atuam com temas da coletividade e com enfoques específicos. Estas ONGs ficaram conhecidas como ONGs militantes/cidadãs, porque juntamente com os movimentos sociais inseriram o conceito e a cultura de cidadania, algo que, na época, era inovador, porque a sociedade brasileira vinha de uma ditadura militar, onde a tradição do país era centralizadora, autoritária, patrimonial e clientelista. Estas atitudes possibilitaram uma abertura política, principalmente nos espaços urbanos das cidades.

As ONGs militantes, que até então tinham como tradição ser contra o Estado, após a promulgação

\footnotetext{
${ }^{8}$ A distinção entre Sociedade Civil e Terceiro Setor é mais de forma e de origem conceitual do que propriamente substantiva. A literatura que utiliza o primeiro termo situa-se mais no mundo da ciência e da filosofia política e tem uma longa tradição no debate da filosofia política, desde o século XVIII, quando Hegel elegeu Sociedade Civil como expressão máxima do desenvolvimento social. A expressão Terceiro Setor, por sua vez, situa-se mais no âmbito das ciências administrativas, do planejamento organizacional e das teorias organizacionais. Se a primeira expressão faz contraponto ao Estado, como espaço da gestão do bem comum, a segunda se refere mais a um contraponto, simultaneamente, ao Estado e ao mercado. Entendido aquele como primeiro setor e este como segundo setor. Assim, as organizações que não constituem o Estado e não são agentes econômicos formariam o Terceiro Setor. (ROSSY, 2006, p. 48)
}

da nova Constituição em 1988, mudaram o seu foco de atuação?.

Na década de 1990 surgiram as ONGs de perfil executivo. As organizações tinham parceiros empresariais, relacionavam-se com grupos econômicos e promoviam ações com personalidades artísticas e esportivas. Rebechi (2002) entende sobre o período que:

As novas ONGs [depois da Constituição de 1988] não gostavam de ser confundidas com as militantes [antes da Constituição de 1988] e, por esta razão, autodenominavam-se simplesmente como Terceiro Setor. O grau de profissionalismo era alto: técnicas empresariais de organização, gestão administrativa de mercado, estratégia de marketing, uso de mídia, divulgação de planos e resultados ${ }^{10}$.

Rebechi (2002) afirma que o compromisso profissional das ONGs, depois da Constituição de 1988, teve como base a capitalização de recursos. Para a autora, por mais que as ONGs fossem sem fins lucrativos, não podiam desperdiçar dinheiro de parceiros e financiadores ${ }^{11}$. Desta forma, o planejamento estratégico em comunicação e administração de empresas se tornaram eixos sobre os quais se estruturaram a gestão das ONGs. O impacto desse perfil logístico foi o da instauração de uma lógica de lucro, de bons indicadores, de prazos, de resultados e até de competitividade no Terceiro Setor.

Rebechi (2002) declara que alguns funcionários de ONGs trabalhavam com rendimentos, em alguns casos, melhores do que da iniciativa privada ${ }^{12}$. A autora relembra que o período teve também a institucionalização de trabalho voluntário ${ }^{13}$.

\section{A Cidadania e a Comunicação Social}

A noção de Cidadania, em seu sentido ideal e normativo, implica o estabelecimento de regras sociais igualitárias e universais relativas ao papel social do indivíduo. Todos os cidadãos têm os mesmos direitos, baseados em princípios de

\footnotetext{
9 REBECHI, Mônica. Agência de Notícias dos Direitos da Infância ANDI Um Estudo Preliminar de uma Organização do Terceiro Setor. Dissertação (Mestrado em História), Mackenzie. 2002. p.12

${ }^{10}$ REBECHI, 2002, p. 13.

${ }^{11}$ Ibidem.

12 Consideramos que as ONGs também são iniciativas privadas e, por isso, esclarecemos que a afirmação da autora é a de que os trabalhadores das ONGs começaram a ter um salário até mais alto que o das empresas de iniciativa privada.

${ }^{13}$ Op. cit.
} 
igualdade e justiça em qualquer espaço social. $\mathrm{O}$ conceito elaborado por Marshall (1967) refere-se ao processo histórico de conquista e expansão os direitos ${ }^{14}$.

Consideramos que, por vezes, a Cidadania é vivida e validada pela atividade profissional do jornalista, tendo em vista a mediação simbólica exercida pelo jornalismo no espaço público.

Neste sentido, Santos (2007) declara que:

As organizações do Terceiro Setor, originárias da Sociedade Civil, institucionalizaram-se numa década marcada pela profissionalização deste setor. No momento seguinte, se veem com dois grandes desafios: buscar visibilidade midiática a fim de legitimar suas lutas e dominar as técnicas de comunicação para convencer seus públicos e seus investidores. Nessa busca de novos conceitos, passando da comunicação alternativa para a institucionalizada e na caminhada pela profissionalização das práticas comunicacionais o papel do jornalista torna-se decisivo como ponte e diversas organizações, também do terceiro setor, surgem para oferecer suporte na construção dessa ponte ${ }^{15}$.

Em Jornalismo da Boa Notícia: Cidadania e Noticiabilidade, VIDAL (2003) considera que os veículos de comunicação são instituições sociais que prestam serviços à sociedade e que têm também uma responsabilidade social e, por isso, devem estar a atentos às notícias de interesse público em sentido amplo $^{16}$. Para a autora, se esta premissa for seguida, haverá a promoção do que ela conceitua como Jornalismo da Boa Notícia ${ }^{17}$ : informações que visam não só o conhecimento da realidade, mas o bem-estar social. É a notícia que não se esgota no fato, mas apresenta uma referência de cidadania e de serviço ${ }^{18}$.

Vidal (2003) afirma que o público leitor ${ }^{19}$ tem a necessidade de um noticiário menos marcado pelo denuncismo e males da realidade em relação aos problemas sociais ${ }^{20}$. A proposta da autora é oposta

\footnotetext{
${ }_{14}$ MARSHALL, T. H. Cidadania, classe social e status. Rio de janeiro, Zahar, 1967.

15 SANTOS, Ana. A questão do conhecimento na cobertura sobre infância e adolescência. Disponível em www.intercom.org.br. Acesso em: 12-122007. Sem registro de publicação. Utilizaremos a data de acesso do texto.

${ }^{16}$ VIDAL, Délcia. Jornalismo da boa notícia cidadania e noticiabilidade. Dissertação (Mestrado em Comunicação), UNB. 2003. p.107

17 VIDAL, 2003. p. 13.

18 Ibidem.

${ }^{19}$ Esse público leitor é o de mídia impressa.

20 Op. cit.
}

ao velho jargão jornalístico americano: "the bad news is good news " ${ }^{21}$. A partir dessa perspectiva da boa-notícia, ou da notícia cívica, podemos associar o conceito de Comunicação Pública ao de Jornalismo Público.

\section{A Cidadania e o Jornalismo Público}

O Jornalismo Público é um modelo de jornalismo que resgata os princípios de Cidadania e ação social do jornalista ${ }^{22}$. A expressão brasileira, Jornalismo Público ${ }^{23}$, é adaptado do inglês Civic Journalism.

O modelo de Jornalismo Público resgata o contato entre o jornalista e o mundo social, mais especificamente a comunidade na qual está inserida a notícia a ser veiculada pelos meios de comunicação. A perspectiva é a de que o jornalista participe de discussões dos temas de interesse público, mais do que dos temas de interesse corporativo (de um mercado noticioso ou da empresa jornalística na qual atua).

O modelo de Jornalismo Público, além de colocar o jornalista em contato com a comunidade, traz as reivindicações do cidadão para o noticiário midiático. Tal fato contribui para a alteração dos valores-notícia. Consideramos que o modelo de Jornalismo Público recupera o aspecto positivo e construtivo da notícia ${ }^{24}$, afastando-se do paradigma no qual o jornalista é um mero informante da sociedade sem ter contato com ela. Contudo, muitos realizadores do Jornalismo Público não estão nas redações tradicionais.

Silva (2004) considera a Agência de Notícias dos Direitos da Infância (ANDI) o melhor exemplo brasileiro de experiência nessa modalidade ${ }^{25}$. Para o autor:

\footnotetext{
${ }^{21}$ Jargão do meio jornalístico americano que sugere ser a tragicidade um critério de noticiabilidade e um valor-notícia.

${ }^{22} \mathrm{O}$ conceito de Jornalismo Público é considerado recente, no Brasil e no mundo, pois tem aproximadamente vinte anos. A perspectiva jornalística revelada por esse modelo de jornalismo é uma das grandes revoluções recentes no campo jornalístico. Depois do advento do modelo de Jornalismo Informativo (critérios de Objetividade), o New Journalism e o Civic Journalism (Jornalismo Público) se impõem como os modelos mais influentes de jornalismo.

${ }^{23}$ A acepção de público do conceito em nada tem a ver com o governo. $\mathrm{O}$ significado é de civismo.

${ }^{24} \mathrm{O}$ modelo de Jornalismo Informativo, dos critérios de Objetividade, posicionava o jornalismo como Quarto Poder, o Cão de Guarda vigia da democracia (Watchdog). A partir da adoção dessa perspectiva, os jornalistas passaram a estar em estado permanente de alerta e crítica às instituições públicas. Uma ideia quase militante de oposicionismo. A postura jornalística de contestação e contra-argumentação se tornou hegemônica. Com isso, o noticiário não teve mais abertura para os temas cívicos.

25 SILVA, 2003, p. 35.
} 
A ANDI, com apoio do UNICEF e de outras parcerias mantém na capital do país uma das maiores redações produzindo notícias que são enviadas para todos os veículos brasileiros de comunicação, além de estar permanentemente realizando pesquisas, publicando estudos e relatórios, bem como treinando jornalistas para a compreensão e cobertura do Estatuto da Criança e do Adolescente, sua principal razão de existir ${ }^{26}$.

Consideramos que os temas cívicos necessitam ser compartilhados simbolicamente no Espaço Público: no caso da ANDI, ela agencia notícias da infância e da adolescência numa prática jornalística sem fins corporativos, mas sociais; e também consideramos que o modelo Jornalismo Público confere visibilidade aos temas da infância e da adolescência por meio da notícia: o prêmio Jornalista Amigo da Criança é uma ferramenta neste sentido.

\section{Prêmio Jornalista Amigo da Criança como agenciamento da cidadania}

O prêmio Jornalista Amigo da Criança tem como objetivo oferecer oportunidades de aperfeiçoamento, treinamento e capacitação de profissionais em relação aos temas sociais da infância e da adolescência, o que a ANDI classifica como pedagogia social $^{27}$.

O prêmio Jornalista Amigo da Criança concedido ao jornalista invoca maior compromisso social ${ }^{28}$ do titulado com a promoção da pauta da criança e da adolescência. Tal medida visa tirar o profissional do paradigma de mero informante da sociedade para o de cidadão: no cumprimento do papel de responsabilidade social do jornalismo ${ }^{29}$, em sociedades democráticas.

O objetivo do prêmio Jornalista Amigo da Criança é o de:

Reconhecer profissionais de comunicação cujo trabalho é pautado pelo compromisso com a agenda social e os direitos da criança e do adolescente ${ }^{30}$.

\footnotetext{
${ }^{26}$ Ibidem.

${ }^{27}$ Perspectiva na qual organismos do Terceiro Setor ensinam a mídia como reportar dado tema. Fonte: www.andi.org.br

${ }^{28}$ Não à toa, os critérios de avaliação do jornalista para diplomação como Jornalista Amigo da Criança levam em conta o compromisso do jornalista com a agenda social e o tema da infância e da adolescência.

${ }_{29}$ Perspectiva construcionista e na linha de dimensão simbólica, influenciada principalmente por BOURDIEU (1998).

${ }^{30}$ www.andi.org.br, visitado em 12-12-2007.
}

Favorecer a especialização dos profissionais, o que caracteriza o projeto como uma ação de capacitação profissional, além de ampliar a rede de Jornalistas Amigos das Crianças, reconhecendo o trabalho de qualidade de jornalistas na cobertura dos temas relativos à infância e à adolescência, através de diplomação pública ${ }^{31}$.

Silva (2004) qualifica o papel da ANDI relativo ao engajamento dos profissionais da seguinte forma:

\begin{abstract}
A ANDI, com apoio do Unicef e de outras parcerias, destacando-se o Instituto Ayrton Senna, entre elas, mantém na capital do país uma das maiores redações (embora com um percentual elevado de estagiários) produzindo notícias que são enviadas para todos os veículos brasileiros de comunicação, além de estar permanentemente realizando pesquisas, publicando estudos e relatórios, bem como treinando jornalistas para a compreensão e cobertura do Estatuto da Criança e do Adolescente, sua principal razão de existir.
\end{abstract}

$\mathrm{Na}$ verdade, trata-se de um jornalismo engajado e esta expressão talvez fosse a que melhor traduzisse no Brasil o espírito do jornalismo público norte-americano, ressalvando-se que, hoje, tal 'engajamento' difere imensamente dos tempos em que o jornalismo engajado significava o jornalismo de combate à ditadura ${ }^{32}$.

Rebechi (2002) declara que o intuito da ANDI é o de formar um "espaço de diálogo ético, profissional e transparente, onde cada um desempenha o seu papel" ${ }^{\prime 33}$. Para a autora:

A ANDI não deseja formar jornalistas engajados e militantes pela causa dos direitos da infância, e sim jornalistas que assumam a responsabilidade de fazer um jornalismo melhor, um jornalismo plural, que ouça todas as vozes, que seja independente e crítico [...] uma vez que é uma agência formada por jornalistas e não por militantes sociais querendo obrigar a imprensa a divulgar os seus conceitos.

Esta postura dá credibilidade ao trabalho, pois a ANDI defende um bom jornalismo para que possa alcançar a defesa dos direitos da criança. ${ }^{34}$

Silva (2007) retrata os principais objetivos de iniciativa de ação social relativos ao agendamento de notícias na mídia:

\footnotetext{
31 Ibidem.

32 SILVA, 2004, p. 32

33 REBECHI, 2002, p. 55.

34 Ibidem.
} 
É preciso destacar que, em geral, grandes "ações sociais" demandam, para além do agendamento das estratégias nos planos das políticas sociais e das políticas públicas, um agendamento específico com relação à mídia, de forma a se obter junto à mesma três tipos de respostas:

-a publicação de notícias;

-a publicação de notícias, acrescidas de serviços: informações de utilidade pública e instruções quanto a procedimentos a serem adotados pelos públicos;

-o estabelecimento de parcerias com a mídia, o que, por vezes, implica em alguma coisa a mais do que a simples sensibilização ${ }^{35}$.

Rossy (2006) afirma que um processo de mobilização social deve contemplar prioritariamente a adesão da mídia ${ }^{36}$ para que esta lhe confira legitimidade e possibilite a adesão de outros atores sociais. Esta legitimidade, por sua vez, irá permitir a inserção do tema na arena pública de discussão e debate ${ }^{37}$.

\section{Representação da Infância e da Adolescência no Jornalismo}

A imagem da criança e do adolescente no jornalismo é codificada em enquadramentos temáticos de acordo com os padrões estabelecidos pelo Estatuto da Criança e do Adolescente - $\mathrm{ECA}^{38}$. Souza (1999) ${ }^{39}$ afirma que

O sentimento da infância identificado no jornalismo é a estrutura fundamental do discurso, sua organização principal, as relações mínimas pro-

\footnotetext{
${ }^{35}$ SILVA, Luiz Martins da. Sociedade, esfera pública e agendamento. In: BENETTI, Márcia; LAGO, Cláudia. (Org.). Metodologia de pesquisa em jornalismo. 1 ed. Petrópolis: Vozes, 2007.

${ }^{36}$ Entendemos a "adesão da mídia", proposta pela autora, aplicada agora ao caso do Jornalista Amigo da Criança, como sendo feita pelos jornalistas diplomados: aqueles que aderem à defesa e promoção dos direitos da infância e da adolescência.

${ }^{37}$ ROSSY, Elizena. Contra-agendamento o Terceiro Setor pautando a mídia. Acessado em 05-12-2007. Disponível em www.fafich.ufmg.br

${ }^{38}$ A mudança do enquadramento da criança e do adolescente com o ECA fez com que os jornalistas mudassem algumas enunciações do noticiário: o termo "prostituição de menores" ou "prostituição infantil" (tidos com pejorativos por enquadrar a criança e o adolescente como agentes de prostituição) foi substituído por "exploração sexual de crianças e adolescentes" em grande parte da mídia (conotação mais branda e passiva que conota injustiça imposta à criança e ao adolescente).

SOUZA (1999) fez um estudo que analisava o discurso sobre a pauta da infância em 482 matérias jornalísticas durante 730 dias em jornais $(O$ Globo, Jornal do Brasil, O Dia, Folha de São Paulo, Tribuna de Minas); e 96 semanas em revistas (Isto é e Veja). A autora trabalha algumas classificações relativas à pauta que usaremos no nosso estudo.
}

dutoras de sentido, as idéias que orientam todo o relato, que são retomadas em todos os momentos do discurso. Os argumentos principais de sustentação, do discurso jornalístico são os sentimentos de proteção e riscos, mito da infância feliz inocência e infância perdida ${ }^{40}$.

$\mathrm{Na}$ classificação de Souza (1999), com referência à pauta Proteção e Riscos, a mídia ${ }^{41}$ se coloca como adulto tendo um olhar de que a criança está sempre em risco. Para a autora, desta forma, o jovem sempre está na iminência de sofrer acidentes, abuso sexual, sequestro, maus tratos, vícios, doenças e violência.

Souza (1999) considera que no cotidiano jornalístico exista "ampliação da pessoa infanto-juvenil no enquadramento dos assuntos no noticiário"42. $\mathrm{Na}$ pauta jornalística, de enquadramento Proteção e Riscos, "as crianças estão expostas a terem doenças antes consideradas somente dos adultos, como stress, depressão, hipertensão, obesidade, diabetes, AIDS e câncer"43.

Segundo Souza (1999), o jornalista se posiciona como um adulto que olha para a criança. $\mathrm{O}$ jornalista a vê como "plenamente feliz no seu estado infantil, lúdico, dependente" ${ }^{44}$. A autora considera que "algumas lembranças relatadas da infância são fantasias adultas"

Souza (1999) afirma que existe a pauta do Mito da Infância Feliz no noticiário. Baseada no conceito de Amnésia Infantil ${ }^{46}$, da Psicanálise, a autora identifica um fenômeno comum ao noticiário jornalístico ${ }^{47}$ :

Os relatos trazem uma esfera de conto de fadas interrompido para as histórias pessoais retratadas na notícia. Tal fato gera oferta de matérias que tratem da perda da inocência e da própria infância apoiadas numa justificativa viciosa [...]. A falta

${ }^{47}$ O conceito de "Amnésia Infantil" trata de fenômeno que afeta a vida adulta. $\mathrm{O}$ adulto acha que a infância é um período mais feliz. A pessoa acredita que a criança é mais feliz por não ter sofrimentos e responsabilidades. $\mathrm{O}$ que seria um engano, pois a percepção dos problemas não era aguçada na infância. SOUZA acredita que o jornalista gera um mito de que a infância é mais feliz que a vida adulta e retrata a criança com problemas sociais como vítima.
} 
de infância é também usada como justificativa para desvios no comportamento de adolescentes e adultos. Menores infratores, criminosos e viciados, normalmente são descritos pelos meios de comunicação como pessoas que não tiveram infância. A falta de infância marca para sempre a vida do adulto ${ }^{48}$.

Souza (1999) acredita que a pauta da infância e da adolescência mostre os personagens frequentemente no papel de vítimas e de forma prodigiosa. " $\mathrm{O}$ aspecto pródigo aparece em notícias que valorizam o espetacular e um talento precoce das crianças" ${ }^{49 ; 50}$. O que já é sabido por alguns organismos do Terceiro Setor que tentam mudar a representação da criança e do adolescente no noticiário.

$\mathrm{O}$ tratamento adequado do noticiário acerca do universo infanto-juvenil valida os preceitos do Estatuto da Criança e do Adolescente. A abordagem temática no noticiário promove a consolidação de um sistema de garantias de direitos implementada pelo ECA.

\section{Santos (2007) prescreve que:}

Conforme consta na Constituição Brasileira, a mídia tem, enquanto parte da sociedade e em conjunto com a família e o Estado, o dever de assegurar à criança e ao adolescente, com absoluta prioridade, o direito à vida, à saúde, ao lazer, à profissionalização, à cultura, à dignidade, ao respeito, à liberdade e à convivência familiar e comunitária, além de colocá-los a salvo de toda forma de negligência ${ }^{51}$.

O guia The Media and Children's Rights, cartilha editada pelo Fundo das Nações Unidas para a Infância (UNICEF) e pela Federação Internacional

\footnotetext{
48 SOUZA, 1999, p. 45.

${ }^{49}$ O aspecto pródigo, do qual trata SOUSA (1999), não recebe exemplos em sua pesquisa. Consideramos que sejam notícias como esta: "Criança de três anos compra carro em eBay". Trata-se do caso de um garoto inglês, Jack, de três anos que aproveitou um descuido da sua mãe e comprou um carro de US\$ 17 mil no site de leilões eBay. (Notícia veiculada em 02-102011. Fonte: www.estadao.com.br). Este exemplo é de notícia internacional. Não é objeto de análise de SOUZA (1999), mas serve de ilustração para a conotação do termo "talento precoce" dado o ineditismo da matéria e falta de exemplos no texto original.

${ }^{50}$ A título de ilustração, em virtude das crianças em efeitos pródigos abordadas por SOUSA (1999), citamos outra notícia do gênero exposto pela autora: "Garoto vestido de homem-aranha salva bebê em Santa Catarina". Trata-se do caso de um garoto, Riquelme dos Santos, de apenas 5 anos, que, fantasiado de Homem-Aranha, entrou em uma casa no meio de um incêndio para salvar um bebê, de 1 ano e 10 meses. (Notícia veiculada 10-11-2011. Fonte: www.estadao.com.br ). Novamente, esclarecemos que as notícias expostas aqui são a título de ilustração e não fazem parte do original de SOUSA (1999).

51 Op. Cit.
}

de Jornalistas (FIJ), convenciona a cobertura jornalística em tópicos:
1) crianças com deficiências;
2) discriminação;
3) crianças na família;
4) trabalho infantil;
5) crianças e conflitos armados;
6) cuidados de saúde e bem-estar;
7) questões de identidade;
8) opiniões e liberdades civis;
9) serviços de assistência pública;
10) crianças e media;
11) crianças nos media;
12) educação;
13) crianças e crime;
14) abuso sexual e exploração;
15) responsabilidades do Estado ${ }^{52}$.

O guia tem influência em países ocidentais. As diretrizes temáticas da cobertura da infância e a da adolescência chegam às redações diretamente pela via da FIJ ou pelo agendamento de notícias feito pelas ONGs que trabalham com a criança e o adolescente. Apesar dos quinze tópicos do documento, para Souza (1999) eles aparecem enquadrados no noticiário em cinco temas: Saúde, Moral, Educação, Sexualidade e Violência infantil.

No tema de Saúde, observa Souza (1999) que o discurso jornalístico se refere às ciências aplicadas, principalmente medicina, deixando de lado as ciências humanas ${ }^{53}{ }^{54}$. O foco do noticiário é o de crianças enfermas com doenças graves, como: diabetes, hipertensão, stress e depressão. A autora considera um equívoco jornalístico tratar as crianças e adolescentes enquadrados apenas nesses tipos de enfermidades. A crítica de SOUZA (1999) é a de que "o noticiário esquece a realidade do Brasil das crianças que morrem de diarreia e fome" 55 .

No tema da Educação, Souza (1999) não identifica "grandes problemas" 56. A autora reconhece como eixos da cobertura: a educação escolar formal e a edu-

\footnotetext{
${ }^{52}$ PONTE, Cristina. Crianças como matéria jornalística In: Crianças em notícia: a construção da infância pelo discurso jornalístico. Lisboa. ICS. Imprensa de Ciências Sociais, 2005. p. 38.

53 SOUZA, 1999, p.66.

${ }^{54}$ O noticiário em Saúde, sobre crianças e adolescentes, não costuma ter abordagens sociológicas sobre epidemias, psicológicas sobre o perfil dos enfermos. Os dados utilizados no noticiário costumam ser majoritariamente os da medicina: posologia, erradicação, tratamento etc.

55 Ibidem.

${ }_{56}$ A autora critica arduamente a tematização utilizada no noticiário e considera que os erros encontrados na abordagem de Educação não sejam expressivos.
} 
cação familiar. Segundo Souza (1999), "as orientações domésticas de como criar os filhos são mais frequentes do que as matérias de cunho colegial".

O tema da Sexualidade, segundo Souza (1999), ainda é tabu. A autora considera que a abordagem no noticiário acontece somente em relação à erotização infantil, à exploração sexual de crianças e adolescentes, à pedofilia na internet, à iniciação e à educação sexual infanto-juvenil ${ }^{57 ; 58}$.

Souza (1999) considera a tematização da pauta da infância e da adolescência operacionalizada por três funções distintas de abordagem: Informativa, Denuncista e Didática.

A Função Informativa trata de temas dos filhos em relação aos pais. Para Souza (1999), esse tipo de cobertura oferece grande volume de informações: "um jornalismo enciclopédia, volumoso, explicativo e variado onde o jornalismo opinativo, interpretativo ou investigativo são raros" ${ }$.

O gênero textual mais usado na abordagem de Função Informativa é o da notícia. Tem espaço nas editorias de política e economia. Os relatos têm perfil de denúncia, mas não são resultado de investigação jornalística ${ }^{60}$. Souza (1999) avalia que:

Muitas matérias com caras de investigativas, mas estão simplesmente reproduzindo as investigações e denúncias de algum grupo ou instituição ${ }^{61}$. Tal fato, faz dos veículos meros "porta-vozes"

A Função Denuncista aborda a criança e o adolescente como vítima de exploração sexual, trabalho infanto-juvenil, analfabetismo e violência. Souza (1999) esclarece que a fonte de informação para as denúncias costumam ser relatórios da ONU, do UNICEF e da OMS. A autora afirma que existe um fluxo de informação oriunda das ONGs que trabalhem com o tema ${ }^{63 ; 64}$.

\footnotetext{
${ }_{57}$ Somam-se temas de cunho moral no noticiário relacionados à moral, ao aborto, estupro, vício, suicídio, problemas amorosos e medidas sóciocorretivas para infratores.

${ }^{58}$ A autora não classificou metodicamente quais tipos de abordagem não são feitas no noticiário, o que indicaria a resistência "tabu" de não cobri-los. SOUZA (1999) só relata dois: notícias sobre incesto e estupro no ambiente familiar.

59 Ibidem.

${ }^{60}$ Denúncias de entidades recebem tratamento noticioso, pela Função Informativa de abordagem da pauta, com leve conotação de denúncia: "Unicef alerta para risco de morte de 90 mil crianças na Somália" e " $85 \%$ de crianças sofrem violência".

61 Ibidem.

62 SOUZA, 1999, p 107.

${ }^{63}$ Ibidem.

${ }^{64}$ Por terem como base estudos e relatórios de entidades, as denúncias no
}

Na Função Denuncista, as notícias não levam em conta o trabalho investigativo do Ministério Público, Conselhos Tutelares e IBGE. Souza (1999) acredita que essas entidades são citadas em relação a medidas a serem adotadas para resolução de problemas e não como fonte de denúncia sobre o problema. Para a autora, "o noticiário retoma a denúncia, passado algum tempo, ao verificar se houve soluções" 65 .

A Função Didática é a mais comum no noticiário. Na avaliação de Souza (1999), costuma ser bem contextualizada. $\mathrm{O}$ uso de aspas de especialistas é frequente, pois "dá legitimidade ao discurso jornalístico e um aspecto científico" "6 . A autora identifica uma "intenção moralizadora, isto é, a tentativa de induzir um comportamento social" ${ }^{67}$.

Souza (1999) considera na Função Didática uma já gasta fórmula de noticiar temas introduzindo-os com o chavão "para entender... sempre usado nas abordagens" ${ }^{68}$. Para a autora, esse recurso serve para explicar termos técnicos, relação cronológica dos fatos, abordar fatos históricos que contribuíram para a situação, causas, consequências, como agir, como identificar situações, como procurar ajuda, endereços úteis de serviços, estatísticas, depoimento de personalidade ${ }^{69}$.

Para Souza (1999), nas três funções (Informativa, Denuncista e Didática) há "clara vitimização da criança e do adolescente" ${ }^{\text {" }}$. Para a autora, trata-se de um fenômeno comum à mídia brasileira, dos anos 1990, de reposicionamento da infância e da adolescência. Na sua avaliação:

O discurso jornalístico se vale ainda dos três recursos da retórica de Aristóteles: o logos (argumento lógico), quando usa teorias e a ciência para explicar o mundo infantil; o plathos (apelo à emoção) e o ethos (caráter do retor), quando utiliza a palavra de especialistas para conferir legitimidade. $\mathrm{O}$ discurso da imprensa também se transforma em ato retórico quando utiliza a linguagem para convencer e levar a uma mudança de comportamento, como no caso da função didática ${ }^{71}$.

noticiário costumam ser contextualizadas com tabelas, infografias, imagens, dados estatísticos e todo tipo de recurso.

65 Ibidem

${ }^{66}$ Ibidem.

67 Ibidem

${ }^{68}$ SOUZA, 1999, p 108.

${ }^{69}$ Ibidem.

70 SOUZA, 1999, p 125.

${ }^{71}$ Ibidem. 
Souza (1999) avalia que a dramatização da notícia e a descrição de personagens no noticiário, mesmo com o apelo feito em torno do perfil psicológico da criança e do adolescente, não incorre em sensacionalismo $^{72}$. Para a autora, trata-se de um relato de adulto sobre a criança ${ }^{73}$.

Consideramos que a infância e adolescência tiveram inserção no noticiário dos anos 1990 como protegidas integralmente ${ }^{74}$. Diferentemente da ideia histórica de infratores, a criança e o adolescente passaram a ter espaço próprio no noticiário com a instauração de uma pauta especializada. O jornalista como defensor dos direitos humanos e, em especial, dos direitos e garantias da criança e do adolescente ${ }^{75}$, trabalha em prol da nova imagem da criança e do adolescente instituída pelo ECA.

\section{Amigo é para essas coisas - Cidadania em redes de amparo à criança}

Existem diversas iniciativas de amparo à criança e ao adolescente, tais como: a rede Hospital Amigo da Criança, o projeto Presidente Amigo da Criança, o Prefeito Amigo da Criança, o Site Amigo da Criança (campanha do Ministério Público contra a pedofilia) e uma infinidade de experiências e projetos sobre o tema. Em geral, esses programas e instituições são um esforço da agenda internacional de cidadania promovida pelo Fundo das Nações Unidas para a Infância, UNICEF ${ }^{7}$. Por isso, a expressão "amigo da criança" é tão frequente.

Entretanto, entendemos que a expressão "amigo da criança" não seja oriunda exclusivamente desse âmbito de causas sociais mantidas ou apoiadas pelo UNICEF. Senão, incorreria em dizer que apenas o Terceiro Setor seria responsável por atividades de amparo à criança e ao adolescente. Acreditamos que a denominação "amigo da criança" tenha a influência de organizações da Sociedade Civil, principalmente

\footnotetext{
72 Op. cit.

73 A autora diz serem comuns os termos: "garotada", "criançada", "pimpolho", "pequenos', 'kids", e "pequeninos" nos relatos jornalísticos. (op. cit.).

${ }^{74} \mathrm{O}$ ECA evoca a proteção integral à criança e ao adolescente.

75 CEJ, 2007.

${ }^{76}$ Um marco na agenda da criança foi a criação do Dia Universal da Criança pela Organização das Nações Unidas, ONU. A data é o dia 20 de novembro de 1950, quando vários países aprovaram a Declaração dos Direitos das Crianças. O Brasil já havia instaurado a comemoração em 1924. Mas só em 1960 o dia 12 de outubro se tornou comemorativo no país devido a campanhas de fábricas de brinquedo, como a Estrela.
}

daquelas ligadas ao amparo de menores abandonados e crianças com algum problema de saúde. Não é raro existirem associações de mães e amigos das crianças, como: a Associação dos Amigos da Criança (AMIC), a Associação de Mães e Amigos da Criança Adolescente em Risco (AMAR), a Associação dos Amigos das Crianças com Câncer (AACC/MS), Associação dos Amigos da Criança Autista (AUMA) e a Associação Nacional Amigos da Pastoral da Criança (AAPAC) ${ }^{77}$. E muitas delas não são parceiras do UNICEF.

\section{Conclusão}

O artigo teve como objetivo um panorama deste universo da cidadania, no tocante aos direitos da criança e do adolescente, principalmente no seu aspecto que vincula a atividade jornalística à responsabilidade social, inerente à profissão, pois o jornalista é defensor dos direitos humanos ${ }^{78}$ e das minorias ${ }^{79}$. Neste contexto, organismos do Terceiro Setor atuam no intuito de pautar notícias de cunho cidadão no Espaço Público. O prêmio Jornalista Amigo da Criança figura como uma iniciativa de jornalistas que não estão nas redações comerciais, tradicionais, mas que estão em redações que têm como valores-notícias outro tipo de objetivo: o agenciamento da cidadania.

$O$ furo de reportagem, a preocupação com a concorrência e outras práticas do jornalismo tradicional, tão comum ao Estado (Primeiro Setor) e ao Mercado (Segundo Setor), parecem não encontrar espaço no contexto de Jornalismo Público, ou Jornalismo Cívico, que tem se alocado nas atividades principalmente do Terceiro Setor. Muitas vezes a notícia cidadã não vende jornais, mas melhora a qualidade de vida de pessoas e de grupos

\footnotetext{
${ }^{77}$ Consideramos que o termo "amigo da criança" é tributário da influência de várias áreas: Jurídica, Medicinal, de Serviço Social e da Psicologia. É o que percebemos nas pesquisas de SOUZA (1999), REBECHI (2002), SANTOS (2007), ZIONI (1993), PONTE (2005) e da Organização Mundial da Saúde (OMS). A construção semântica em torno de um grupo de amigos de apoio à criança é feita em vista dos meninos de rua e menores abandonados. Muitas vezes, tais crianças não tinham pais ou familiares. A experiência de abrigo impregnou a ideia de tuteladores ou cuidadores a esse universo. Essa denominação de "amigo da criança" começou a ser feita em relação a pessoas que ajudam as crianças no processo de socialização das casas de amparo ao menor. J. SILVA (2007) afirma que a ausência materna, paterna e parental (de irmãos, avós, tios) incorria num vazio afetivo parcialmente preenchido nas relações com o grupo de amigos. (SILVA, Josenilta. Violência sexual e doméstica contra crianças e adolescentes na imprensa. Dissertação (Mestrado em Serviço Social), UFPE. 2007)

${ }^{78}$ Código de Ética dos Jornalistas Profissionais (1987)

${ }^{79}$ Código de Ética dos Jornalistas Brasileiros (2007)
} 
sociais. Vários organismos trabalham neste sentido de dar visibilidade, no meio social, a temas, valores, pessoas, instituições, legislação e preceitos que podem não interessar ao Estado e nem ao Mercado, mas que, sobretudo, interessam ao cidadão. É este valor a mais que faz parte do dever profissional do jornalista: o de defender os direitos humanos e as minorias. A criança e o adolescente, como figuras de direito, passíveis de gozo de suas garantias, merecem este tipo de atenção e tratamento pelos jornalistas nas suas representações sobre o mundo.

\section{REFERÊNCIAS}

ANDI: comunicação e direitos. Disponível em: <www.andi. org.br>. Acesso em: 12 dezembro 2011.

BRASIL. Presidência da República. Casa Civil. Constituição da República Federativa do Brasil de 1988. Disponível em: <http://www.planalto.gov.br/ccivil_03/Constituicao/ Constitui\%C3\%A7ao.htm>.

Lei $n^{0}$ 8.069, de 13 de julho de 1990. Dispõe sobre o Estatuto da Criança e do Adolescente e dá outras providências. Disponível em: <http://www. planalto.gov.br/ccivil_03/leis/L8069.htm>.

FACULDADE DE FILOSOFIA E CIÊNCIAS HUMANAS. Disponível em: <www.fafich.ufmg.br>. Acesso em 12 dezembro de 2011.

FERNANDES, Rubem César. Privado porém público: o terceiro setor na América Latina. Rio de Janeiro: RelumeDumará, 1994.

INTERCOM. Disponível em: <www.intercom.org.br>. Acesso em 12 dezembro 2011.

MARSHALL, T. H. Cidadania, classe social e status. Rio de Janeiro, Zahar, 1967.

PONTE, Cristina. Crianças como matéria jornalística. In: . Crianças em notícia: a construção da infância pelo discurso jornalístico. Lisboa. ICS. Imprensa de Ciências Sociais, 2005.

REBECHI, Mônica. Agência de Notícias dos Direitos da Infância ANDI: um estudo preliminar de uma organização do terceiro setor. Dissertação (Mestrado em História), Mackenzie. 2002.

ROSSY, Elizena. Contra-agendamento o terceiro setor pautando a mídia. Disponível em: <www.fafich.ufmg.br>. Acesso em: 05 dezembro 2011.

. Mídia e terceiro setor: como as ONGS promovem a cultura de paz. Dissertação (Mestrado em Comunicação), UNB. 2006.
SANTOS, Ana. A questão do conhecimento na cobertura sobre infância e adolescência. Disponível em: <www. intercom.org.br>. Acesso em: 12 dezembro 2011.

SILVA, Luiz Martins da. Sociedade, esfera pública e agendamento. In: BENETTI, Márcia; LAGO, Cláudia. (Org.). Metodologia de pesquisa em jornalismo. Petrópolis, RJ: Vozes, 2007.

SILVA, Luiz Martins (Org.). Comunicação pública. Brasília: Casa das Musas, 2003.

SILVA, Josenilta. Violência sexual e doméstica contra crianças e adolescentes na imprensa. Dissertação (Mestrado em Serviço Social), UFPE. 2007

SOUZA, Marina. Infância de papel: análise do discurso jornalístico sobre a infância na imprensa brasileira. Dissertação (Mestrado em Comunicação), UFRJ. 1999.

VIDAL, Délcia. Jornalismo da boa notícia cidadania e noticiabilidade. Dissertação (Mestrado em Comunicação), UNB. 2003. 